\title{
A Computational Framework Towards Energy Efficient Casting Processes
}

\author{
Michail Papanikolaou, Emanuele Pagone, Konstantinos Salonitis, Mark Jolly and \\ Charalampos Makatsoris \\ Sustainable Manufacturing Systems Centre, Cranfield University, Cranfield, MK43 \\ OAL, United Kingdom
}

\begin{abstract}
Casting is one of the most widely used, challenging and energy intensive manufacturing processes. Due to the complex engineering problems associated with casting, foundry engineers are mainly concerned with the quality of the final casting component. Consequently, energy efficiency is often disregarded and huge amounts of energy are wasted in favor of high quality casting parts. In this paper, a novel computational framework for the constrained minimization of the pouring temperature is presented and applied on the Constrained Rapid Induction Melting Single Shot Up-Casting (CRIMSON) process. Minimizing the value of the pouring temperature can lead to significant energy savings during the melting and holding processes as well as to higher yield rate due to the resulting reduction of the solidification time. Moreover, a multi-objective optimization component has been integrated into our scheme to assist decision makers with estimating the trade-off between process parameters.
\end{abstract}

Keywords: CRIMSON, Sustainability, Computational Framework, Sand Casting

\section{Introduction}

For a long period of time, the performance of manufacturing systems was assessed based on four main decision-making attributes, namely cost, quality, time and flexibility. According to recent reports, the energy consumption of industrial operations accounted for about $24 \%$ of the total global primary energy supply [1] and for about 20 $\%$ of the total $\mathrm{CO}_{2}$ emissions worldwide [2]. It has been therefore clearer than ever that manufacturing systems should be additionally evaluated according to their energy efficiency, which is one of the key factors for sustainable manufacturing systems. These recent developments contributed towards the addition of sustainability to the list of the aforementioned decision-making attributes [3].

During the last decades, the dramatic increase of the world population as well as the need for consumer goods have initiated a more systematic approach towards identifying 
processes and activities with high energy consumption and providing solutions for energy savings. Solutions around energy and sustainability performance can be achieved by following two main strategies: (a) efficient use of fuels and where possible renewable energy sources and (b) development of more efficient and sustainable manufacturing processes.

Casting is one of the most widely used primary metal forming processes. Casting is known for its complexity as it consists of 6 main manufacturing processes, namely melting, alloying, molding, pouring, solidification and finishing [4]. It is also common that heat treatment is implemented as a post-casting process [5]. Besides its complexity, casting has been known for its energy intensity. According to [6], the energy consumption associated with the melting process is equal to $55 \%$ of the total energy consumption. Moreover, according to the same investigation, the energy burden becomes even higher due to the tendency of foundries, which are mainly small businesses, not to take financial risks and invest in new furnace types incorporating advanced technologies with higher thermal efficiency, such as induction furnaces [7]. According to Salonitis et al. [4], some of the proposed methods for energy efficiency in foundries are (a) reducing the holding time, (b) increasing the casting yield and (c) high quality melting.

Resource efficiency in casting is an additional challenge that needs to be addressed. Salonitis et al. [4] used the Operational Material Efficiency (OME) criterion and showed that the yield in traditional sand casting processes is about $27 \%$. The metal loss was associated with the fettling, machining and inspection stages, where up to $90 \%$ of the material was chopped off, up to $25 \%$ of the material was machined off and up to $20 \%$ of the final casting components failed the inspection respectively.

It is therefore of high importance that auditing and analysis tools for measuring the energy and resource efficiency are developed. A systematic effort to perform energy audits to assess the energy efficiency of sand casting foundries has been performed by Mehrabi et al. [8] who proposed a set of energy saving methods towards an energy efficient and sustainable foundry. Computer simulation and Life Cycle Assessment (LCA) analysis have also been performed for the optimization of conventional sand casting processes [9]. Results showed that the novel CRIMSON up-casting process can offer significantly higher energy efficiency and material yield. A computational framework for performing systematic analysis of the energy and material flows in foundries has been developed by Pagone et al. [10]. This tool offers decision makers the opportunity to visualize the material and energy flows in casting processes using Sankey diagrams and identify the casting stages where action must be taken to enhance the overall process efficiency.

Performing energy and material efficiency audits relies on real time data, collected during the manufacturing processes. However, real time data collection is not always feasible due to either the complexity of the processes or confidentiality reasons. This problem was partially overcome with the help of computer simulation. During the past few decades, the exponential growth of the computing power has allowed researchers to perform highly accurate numerical simulations of the behaviour of physical systems. As far as casting is concerned, Computational Fluid Dynamics (CFD) has been extensively implemented for simulating the mold filling and solidification processes. Recent developments have allowed for the numerical modeling of casting, which involves a 
series of diverse phenomena such as heat flow, viscous metal flow with many transient free-surface boundaries, phase change and multiple length- and timescales [11]. The evolution of numerical models has also contributed towards the accurate prediction of casting defects using CFD simulations. More specifically, CFD has been implemented for the prediction of double oxide film defects [12], macroshrinkage [13] and microporosity [14]. According to Ravi [15], CFD has been proven to be particularly useful for 3 main purposes: (a) quality enhancement of final casting components [16], (b) yield improvement by reducing the mass of the feeding and gating channels [17] and (c) rapid development of new casting designs by reducing the number of foundry trials [18]. In addition, CFD simulations have been implemented as a step to build databases of casting process parameters and their effects on the final casting product. These databases have later on been used to train Artificial Neural Networks (ANNs) as simulation metamodels with the help of the Design of Experiments (DoE) method [19]. In a similar study, CFD was combined with the Taguchi method to analyze the sand and methoding related defects in green sand casting and minimize the percentage of rejected final components due to defects. Moreover, an optimized design of the gating and feeding system was proposed [20]. An interesting study has been presented by Keste et al. [21] focusing on the design optimization of the casting shape for the reduction of the residual stresses. For this purpose, the authors solved a constrained multivariable optimization problem with the geometrical parameters of the component as variables while the objective function was the minimization of the residual stresses. Their numerical results were in good agreement with experimental results.

In this study, we have performed CFD simulations in conjunction with an in-house constrained optimization algorithm for the estimation of the minimum pouring temperature that can be used in the CRIMSON process. More specifically, our optimization scheme is grounded on the assumption that the minimum pouring temperature that can be applied is the one for which solidification commences right at the end of the filling process. It is of utmost significance that solidification does not start occurring during the filling process as this will increase the air entrapment into the liquid metal. Casting with the minimum pouring temperature will contribute towards significant energy savings during the melting and holding phases. Our analysis is also extended to the effects of the pouring temperature on the shrinkage microporosity. A multi-objective optimization framework is also proposed for the evaluation of the optimum pouring temperature based on the balance between the desired properties of the final product and the energy efficiency of the process.

\section{Methodology}

\subsection{Introduction}

The Constrained Rapid Induction Melting Single Shot Up-Casting Method (CRIMSON) has been developed by Jolly et al. [22]. The main benefit of this casting method compared to conventional sand casting techniques is reduced energy consumption. CRIMSON uses an induction furnace and the required quantity of metal for filling 
just a single mold is melted. Afterwards, the crucible is transferred to a casting workstation where the molten metal is pushed up with a piston to fill the mold using a computer-controlled counter-gravity filling method. The very short melting, transfer and filling times of the liquid metal contribute towards minimum holding time and consequently (a) significant energy savings are achieved and (b) the quality of the final product is enhanced due to minimal possibility of surface oxide films formation. The design of the simulation geometry which comprises of the mold, the shot sleeve, where the molten metal is initially stored, and the piston is depicted in Fig. 1.

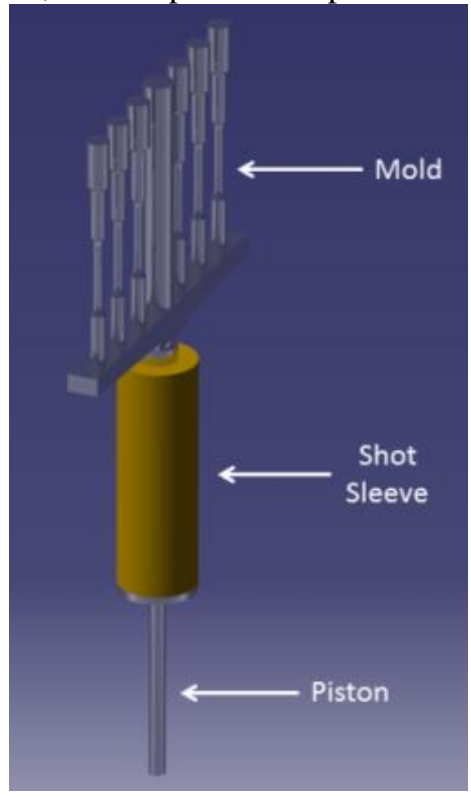

Fig. 1. Schematic representation of the simulation geometry

Optimization frameworks have been extensively implemented in a variety of engineering problems $[23,24]$. The methodology presented in this investigation is schematically represented in the workflow of Fig. 2. Initially, the physical problem is defined by setting up the simulation parameters such as the geometry files of the parts, the mesh and boundary conditions. The aforementioned parameters are stored in a single file which is used as an input for the CFD solver. Before solving the model, error checking is performed. Subsequently, the simulation results are fed to the optimizer using a parser and the new simulation parameters are evaluated and fed back into the CFD software. This task involves editing the input file used by the solver. This loop continues until the desired accuracy in the objective function set for each simulation case is achieved. The Constrained Optimization by Linear Approximation (COBYLA) method and the Non-dominated Sorting Genetic Algorithm-II (NSGA-II) have been implemented for single- and multi-objective optimization case studies correspondingly. At the end of each optimization run, results are ready for post-processing. Further detail on each simulation step will be provided in the following paragraphs. The Flow-3D software [25] was adapted for performing our filling and solidification simulations. 


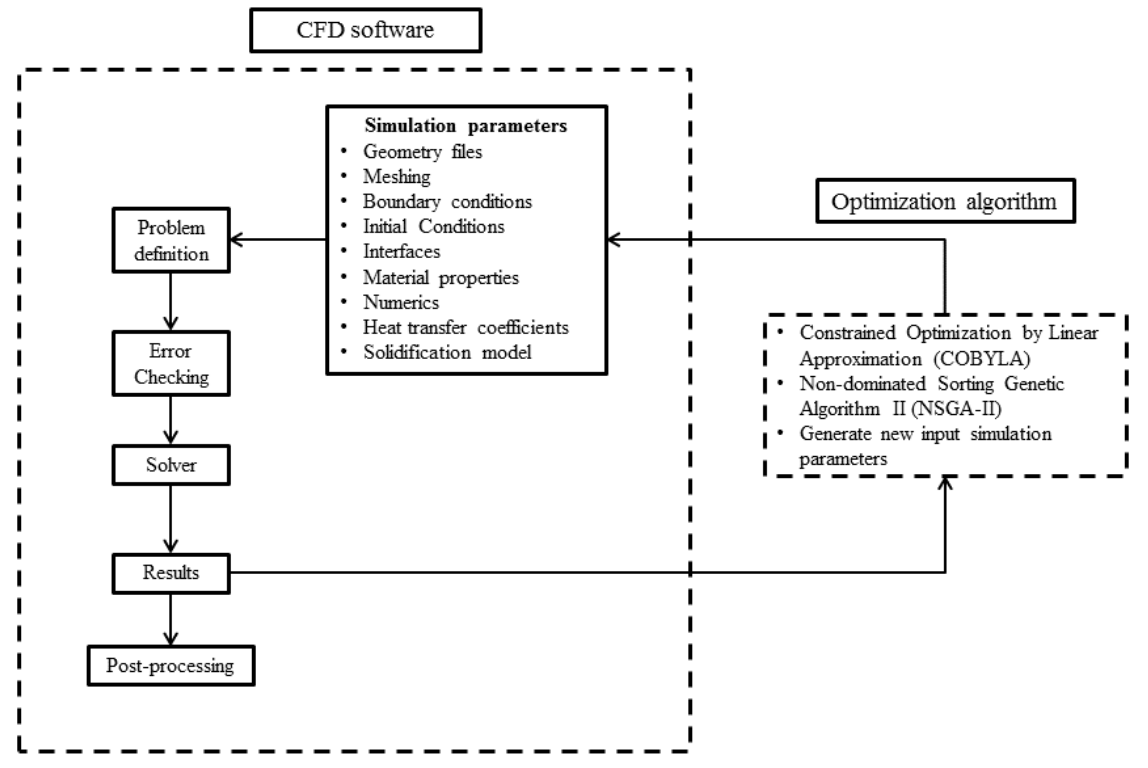

Fig. 2. Workflow of the computational framework

\subsection{Filling and Solidification setup}

The materials that have been assigned to each geometry component are listed on Table 1, while the corresponding material properties have been imported from the Flow-3D materials database. In order to model the air entrainment into the molten metal due to turbulent disturbances, we used the air entrainment model of Flow-3D. The molten metal flow was considered to be viscous and turbulent and the Renormalized Group (RNG) model was used for modelling turbulence. The wall shear boundary conditions were set as no-slip while the surface defect concentration model was implemented to track the surface impurities' formation due to the free surface oxides. The air temperature as well as the initial temperature of the casting components were set equal to 15 ${ }^{\circ} \mathrm{C}$ and the air pressure was defined equal to the atmospheric. The piston velocity was constant and equal to $0.03 \mathrm{~m} / \mathrm{s}$ while the filing process was completed within $10 \mathrm{~s}$.

Table 1. Component materials

\begin{tabular}{|l|l|}
\hline \multicolumn{1}{|c|}{ Component } & \multicolumn{1}{c|}{ Material } \\
\hline Metal & Aluminum Silicon Alloy A356 \\
\hline Mold & Silica Sand \\
\hline Shot sleeve & Ceramic \\
\hline Piston & Ceramic \\
\hline
\end{tabular}

Two different mesh types were applied across the simulation domain as shown in Fig. 3. A fine mesh was applied on the mold domain to achieve accurate results, while a coarser mesh was applied on the rest of the simulation domain to minimize the computational cost. The density of the fine mesh was selected so as to ensure that there are at 
least two mesh cells in the minimum cross section of the casting design. As shown in Fig. 3(a) \& (b) the two meshes were perfectly aligned in the $\mathrm{x}, \mathrm{y}$ and $\mathrm{z}$ directions. In this way, enhanced data transfer between the two mesh blocks is achieved. The boundary conditions imposed on each mesh plane are summarized in Table 2.

(a)

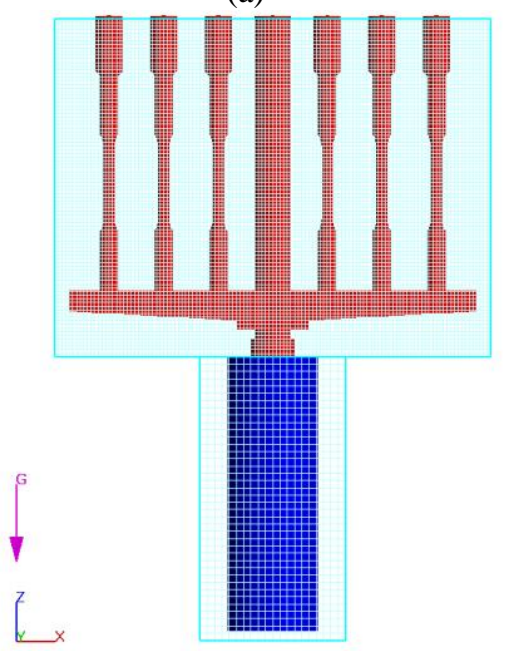

(b)

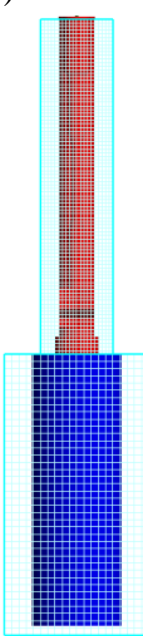

Fig. 3. Computational mesh in the $\mathrm{xz}$ and yz planes

Table 2. Mesh boundary conditions

\begin{tabular}{|l|l|l|l|}
\hline \multicolumn{2}{|c|}{ Fine Mesh } & \multicolumn{2}{c|}{ Coarse Mesh } \\
\hline xmin & Wall $\left(\mathrm{T}=15^{\circ} \mathrm{C}\right)$ & xmin & Wall $\left(\mathrm{T}=15^{\circ} \mathrm{C}\right)$ \\
\hline xmax & Wall $\left(\mathrm{T}=15^{\circ} \mathrm{C}\right)$ & xmax & Wall $\left(\mathrm{T}=15^{\circ} \mathrm{C}\right)$ \\
\hline ymin & Wall $\left(\mathrm{T}=15^{\circ} \mathrm{C}\right)$ & ymin & Wall $\left(\mathrm{T}=15^{\circ} \mathrm{C}\right)$ \\
\hline ymax & Wall $\left(\mathrm{T}=15^{\circ} \mathrm{C}\right)$ & ymax & Wall $\left(\mathrm{T}=15^{\circ} \mathrm{C}\right)$ \\
\hline zmin & Symmetry & zmin & Symmetry \\
\hline zmax & Pressure $\left(\mathrm{P}=1 \mathrm{~atm}, \mathrm{~T}=15^{\circ} \mathrm{C}\right)$ & zmax & Symmetry \\
\hline
\end{tabular}

Our simulations have been divided in two parts: (a) filling and (b) solidification. For the filling simulation the fluid momentum and continuity equations are being solved, while a first-order method is used for the approximation of the momentum advection. For the solidification stage, a zero-velocity field is considered and an implicit solver is used for the heat transfer calculation.

\subsection{Optimization}

As shown in Fig. 2, the main function of our optimization algorithm was to run the following sequence of actions in a loop until the desired accuracy in the objective function was achieved: (a) run a FLOW-3D simulation, (b) parse the FLOW-3D output files and store the values of the output variables under examination, (c) feed those values to the optimizer and (d) generate an input file for the next run using the updated input 
parameters. The Constrained Optimization By Linear Approximation (COBYLA) numerical optimization method, integrated in the SciPy library, was used [26] for the single-objective optimization case study. For the multi-objective optimization case study we implemented the Non-dominated Sorting Genetic Algorithm-II (NSGA-II) [27] integrated in the Platypus library [28].

\section{Results and Discussion}

\subsection{Simulation}
(a) $t=4 s$
(b) $t=6 s$
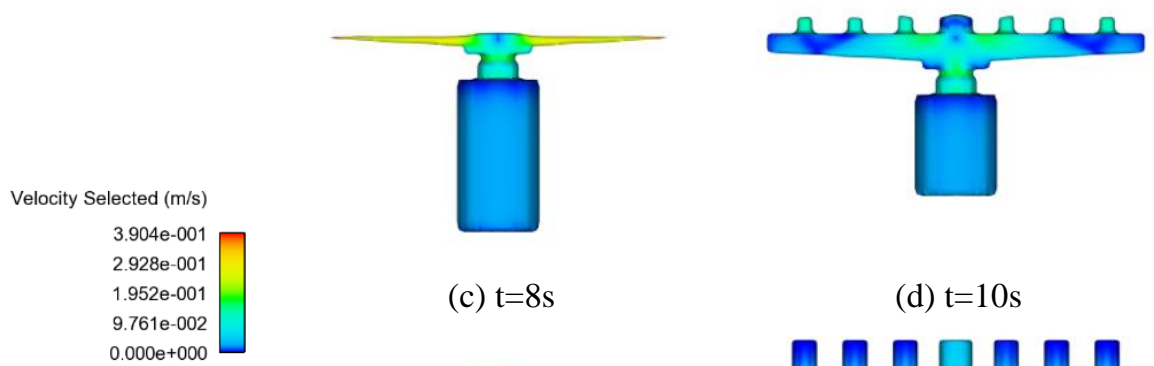

(c) $t=8 s$

(d) $t=10 \mathrm{~s}$
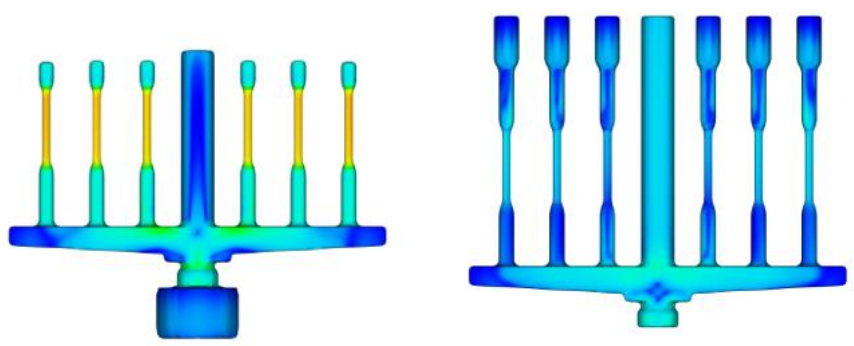

Fig. 4. Velocity magnitude profiles during filling at (a) $t=4 s$, (b) $t=6 s$, (c) $t=8 s$ and (d) $t=10 s$

For the sake of the current analysis we performed an initial simulation of the filling and solidification processes with an initial pouring temperature $\mathrm{T}_{\mathrm{p}}=720{ }^{\circ} \mathrm{C}$. As it can be observed in Fig. 4, filling is very smooth and the maximum velocity magnitude during this process is about equal to $0.4 \mathrm{~m} / \mathrm{s}$ and is located at the minimum cross section of the casting as expected. It is also evident that filling is completed at $t=10 \mathrm{~s}$.

Fig. 5 presents the time evolution of the solidified liquid fraction across the computational domain. First of all, it can be observed that solidification is initiated at 3 locations: (a) the top part of the riser and the tensile bars which are exposed to the atmosphere, (b) the thin cross sections located at the middle of the tensile bars and (c) at the lowest section of the simulation domain which is contact with the piston. Additionally, we can see that the total solidification time $T_{s}$, for a pouring temperature $T_{p}=720{ }^{\circ} \mathrm{C}$, is 
equal to $486 \mathrm{~s}$ or 8.1 minutes. For pouring temperatures higher than $760{ }^{\circ} \mathrm{C}$, the height of the casting geometry is slightly reduced with time. In addition, the height of the riser becomes even lower than the height of the tensile bars. This phenomenon can be attributed to shrinkage and becomes more evident for higher values of the pouring temperature $T_{p}$. It occurs because the riser is the part that solidifies at the end of the process.

(a) $\mathrm{S}_{\mathrm{f}}=0$

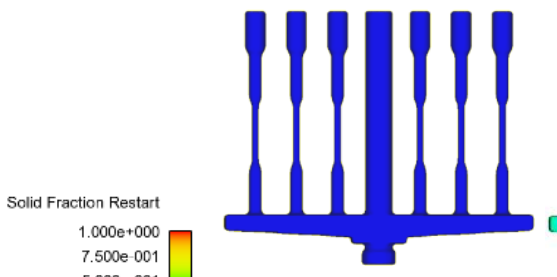

(d) $\mathrm{S}_{\mathrm{f}}=0.6$

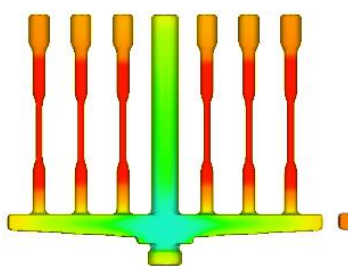

(b) $\mathrm{S}_{\mathrm{f}}=0.2$

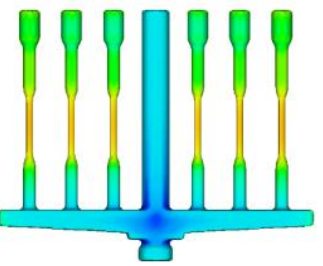

(e) $\mathrm{S}_{\mathrm{f}}=0.8$

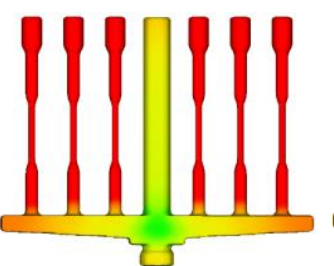

(c) $\mathrm{S}_{\mathrm{f}}=0.4$

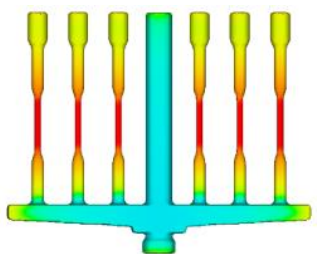

(f) $\mathrm{S}_{\mathrm{f}}=1$

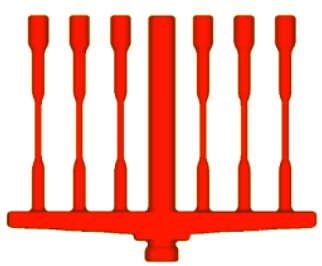

Fig. 5. Solidified liquid fraction at (a) $\mathrm{S}_{\mathrm{f}}=0$, (b) $\mathrm{S}_{\mathrm{f}}=0.2$, (c) $\mathrm{S}_{\mathrm{f}}=0.4$, (d) $\mathrm{S}_{\mathrm{f}}=0.6$, (e) $\mathrm{S}_{\mathrm{f}}=0.8$, (f) $\mathrm{S}_{\mathrm{f}}=1$

\subsection{Pouring Temperature Effects on the Solidification Time and the Casting Quality}

As an initial step, we investigated how the solidification time is affected by the pouring temperature. As observed in Fig. 6(a), the solidification time is approximately a linear function of the pouring temperature for a pouring temperature range between 700 and $800{ }^{\circ} \mathrm{C}$. It is therefore reasonable to conclude that reducing the pouring temperature affects not only the energy efficiency (savings achieved during the melting and holding phases) but the yield as well, because of the reduction of the total casting solidification time.

For this particular investigation, we used shrinkage microporosity as a measure of the casting quality. Shrinkage microporosity is a type of casting defect which is characterized by uniformly distributed bubbles across the casting volume and develops during the later stages of the solidification process. As shown in Fig. 6(b), shrinkage microporosity decreases with increasing pouring temperature for this particular case study. This observation is attributed to the increased local fluidity induced by the higher pouring temperature. Therefore, it can be concluded that lower pouring temperature affects adversely the quality of the final casting component. 
(a)

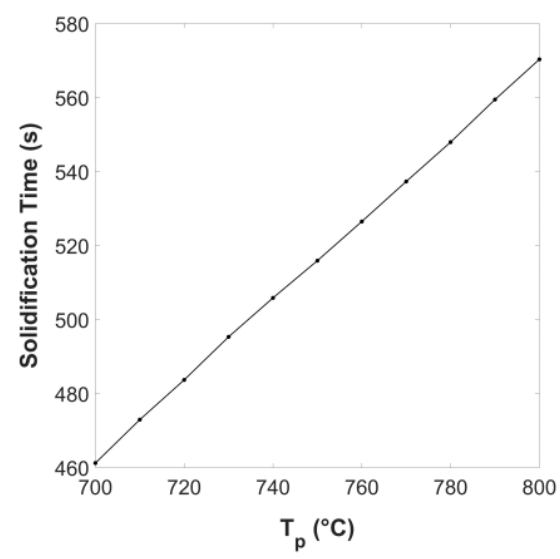

(b)

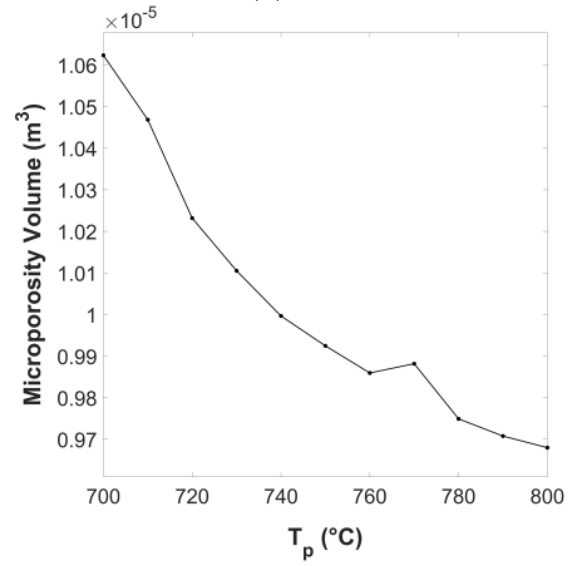

Fig. 6. (a) Solidification time and (b) microporosity volume vs pouring temperature

\subsection{Single-objective optimization}

The results presented in the previous paragraph highlight the need for the development of computational tools assisting foundry engineers to make the right decisions for sustainable manufacturing. To serve this purpose, we developed a computational framework for the optimization of the casting process parameters based on the methodology presented in paragraph 2.3.

For the first optimization case study our goal has been to minimize the pouring temperature to improve the energy efficiency of the casting process. Our optimization objective was to determine the right pouring temperature so that solidification commences right at the end of the filling process. In mathematical terms the optimization problem can be defined as:

- $\quad$ Minimize $f\left(T_{p}\right)$, where $f\left(T_{p}\right)=a b s\left(\left.S_{f}\left(T_{p}\right)\right|_{t=10 s}-0.0001\right)$

- subject to $6500^{\circ} \mathrm{C} \leq T_{p} \leq 750^{\circ} \mathrm{C}$

- $T_{p, 0}=670^{\circ} \mathrm{C}$

where $\left.S_{f}\left(T_{p}\right)\right|_{t=10 s}$ is the solid fraction at the end of the filling process ( $\mathrm{t}=10 \mathrm{~s}$ ) as a function of the pouring temperature and $T_{p, 0}$ is the initial guess of the optimizer.

Fig. 7 illustrates the solution approach by the COBYLA optimizer while the values of (a) the objective function $f\left(T_{p}\right)$ and (b) the pouring temperature $T_{p}$ are plotted against the optimizer iterations. It can be observed that the optimizer has reached close enough to the final solution within just about 13 iterations and that the optimum pouring temperature for the particular case study is equal to $693.74{ }^{\circ} \mathrm{C}$. If a higher value than the optimum is selected, there will be additional energy consumption, while for a lower one, premature solidification will lead to additional defects in the final casting component. 
(a)

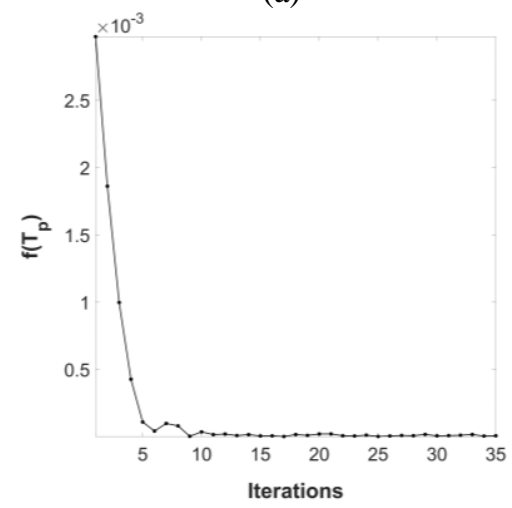

(b)

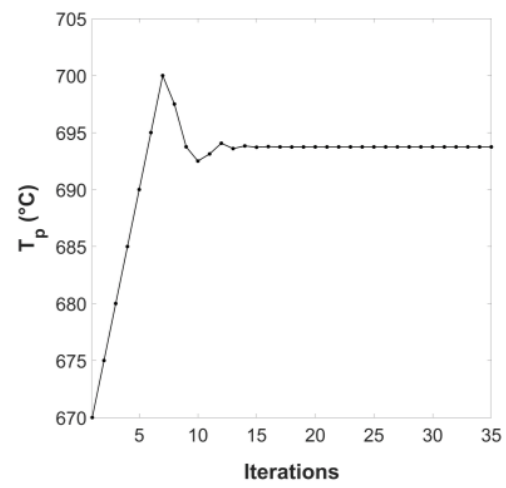

Fig. 7. (a) Value of the objective function and (b) pouring temperature vs the number of iterations

The effects of the minimization of the pouring temperature on the energy efficiency and the solidification time for a batch of $10^{4}$ parts (Sigle line/Mass production) are illustrated in Fig. 8(a) and (b) respectively. Optimized results are being compared against a pouring temperature equal to $\mathrm{T}_{\mathrm{P}}=750{ }^{\circ} \mathrm{C}$. It is evident that the minimization of the pouring temperature contributes to a $4.3 \%$ reduction of the required heat for melting $(1,554 \mathrm{MJ})$ and a $12 \%$ reduction of the total solidification time (172 hours). For the estimation of the heat required to melt the appropriate metal quantity for a single casting component, we used the following formula:

$$
Q=m c_{P} \Delta T+m L
$$

where $Q$ is the total heat required, $m=4.2 \mathrm{~kg}$ is the mass a single casting component, $c_{P}=963 \mathrm{~J} / \mathrm{kg}$ the specific heat of A356, $\Delta T=T_{P}-15^{\circ} \mathrm{C}$ and $L=389 \mathrm{~kJ} / \mathrm{kg}$ the latent heat for the change of state of A356.

(a)

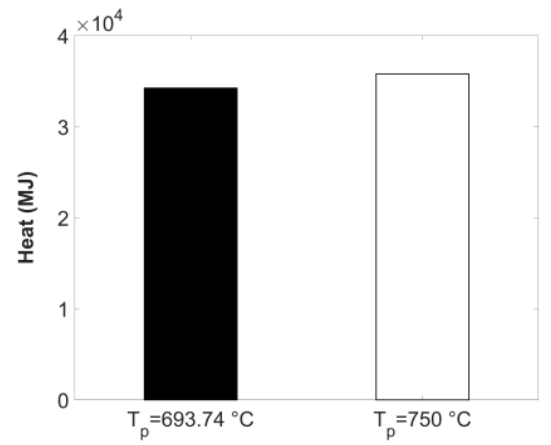

(b)

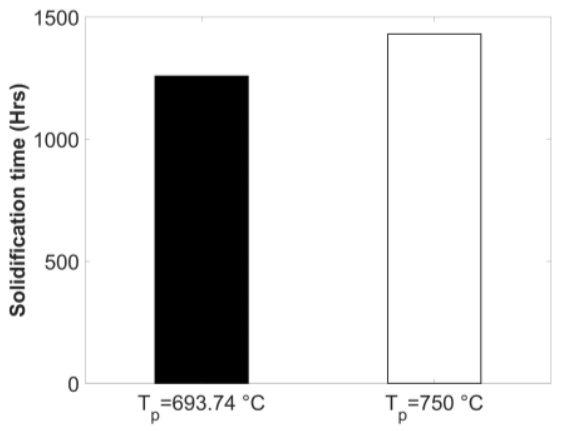

Fig. 8. Comparison between initial and optimized pouring temperature effects on (a) the heat required for melting (b) the solidification time required for 10,000 casting parts (Sigle line/Mass production). 


\subsection{Multi-objective optimization}

In the case of casting, as in any other engineering problem, decisions have to be made based on trade-offs between conflicting objectives. For instance, in this case study, an increase in the pouring temperature will lead to additional energy consumption but on the other hand, higher quality will be achieved due to less shrinkage microporosity (see paragraph 3.2). It is therefore crucial that computational tools for the estimation of these trade-offs are developed. These tools are of great utility when multiple objective functions are under consideration, such as in the case of sustainability, where both product quality and energy efficiency should be maximized.

In this study, we have used the NSGA-II multi-objective optimization algorithm in order to demonstrate the trade-off between the casting quality, measured via the microporosity volume in this case, and energy efficiency. In mathematical terms the optimization problem can be defined as:

- $\quad$ Minimize $\left(f\left(T_{p}\right)\right.$, Microporosity volume)

- $\quad$ subject to $650^{\circ} \mathrm{C} \leq T_{p} \leq 750{ }^{\circ} \mathrm{C}$

The solution of this problem is a set of feasible solutions, also called a Pareto front, which is illustrated in Fig. 9.

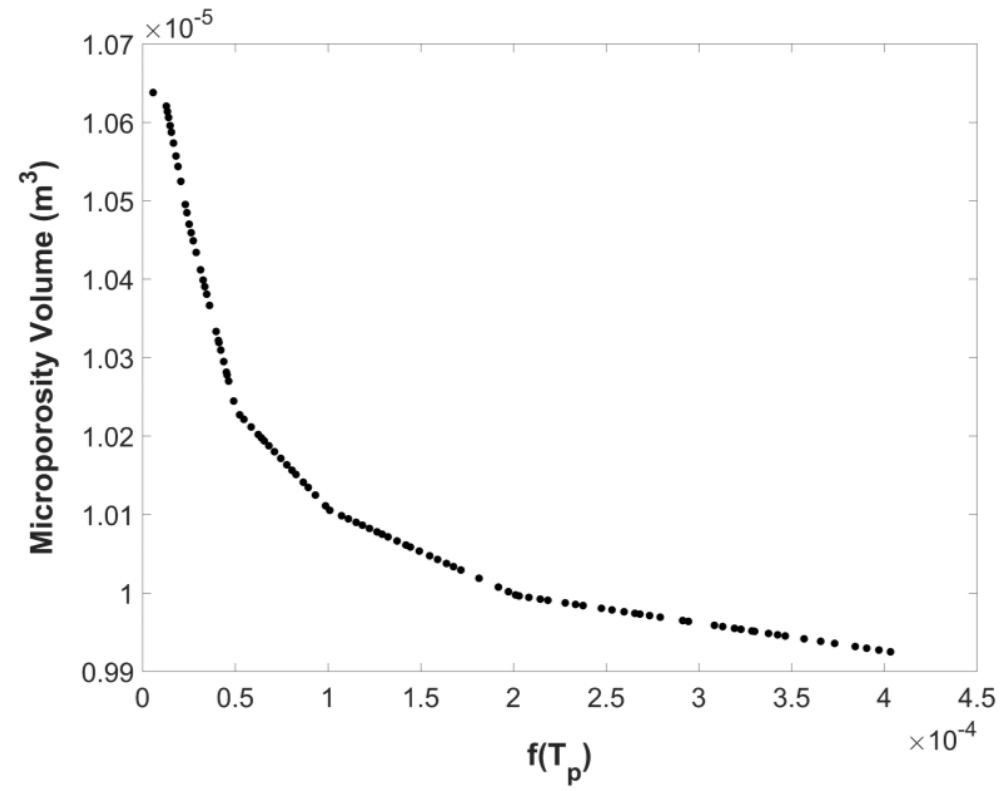

Fig. 9. Set of feasible solutions for the multi-objective optimization problem (Pareto front) 


\section{Conclusions and Future Work}

During the last few decades, sustainability has been consolidated in the decision-making framework of manufacturing processes. However, in the case of sustainable production, many conflicting objectives are involved in the decision-making process. Therefore, the development of computational tools capable of providing decision makers with the required information is more than imperative.

In the current investigation we have developed a computational framework integrating both single- and multi-objective optimization algorithms for the promotion of energy efficient casting processes. Our framework consists of an in-house algorithm plugged into the commercial CFD software Flow-3D. Our computational framework was applied on the CRIMSON casting process and two optimization case studies were performed: (a) a single-objective optimization case study for the minimization of the pouring temperature aiming at enhanced energy efficiency and (b) a multi-objective optimization case study for the demonstration of the trade-off between the energy efficiency and the final cast product quality. Our results suggest that the optimum pouring temperature for the particular casting design is $693.74{ }^{\circ} \mathrm{C}$. Moreover, a Pareto curve is provided for assisting decision makers to select the optimum pouring temperature based on the desired final product characteristics and energy efficiency.

This investigation has briefly shown the potential and benefits of applying a computational framework towards sustainable production. Some future research directions suggested are: (a) the incorporation of more process parameters, such as the geometrical parameters of the mold shape, into the computational framework, (b) the extension of the application of the current framework to other types of casting processes and (c) the evaluation of whether the construction of databases and training of Artificial Neural Networks (ANNs) in favor of faster decision-making process is feasible.

\section{Acknowledgements}

The authors would like to acknowledge the UK EPSRC projects "Small is Beautiful" and "Energy Resilient Manufacturing 2: Small is Beautiful Phase 2 (SIB2)" for funding this work under grants EP/M013863/1 and EP/P012272/1 respectively. 


\section{References}

1. (2017) Key world energy statistics

2. $\mathrm{CO} 2$ emissions from manufacturing industries and construction (\% of total fuel combustion) | Data.

https://data. worldbank.org/indicator/EN.CO2.MANF.ZS?end=2014\&start=19 98.

3. Salonitis K, Ball P (2013) Energy Efficient Manufacturing from Machine Tools to Manufacturing Systems. Procedia CIRP 7:634-639 . doi: 10.1016/J.PROCIR.2013.06.045

4. Salonitis K, Zeng B, Mehrabi HA, Jolly M (2016) The Challenges for Energy Efficient Casting Processes. Procedia CIRP 40:24-29 . doi: 10.1016/J.PROCIR.2016.01.043

5. Campbell J (2015) Complete Casting Handbook: Metal Casting Processes, Techniques and Design

6. Bcs Incorporated (2005) Advanced Melting Technologies: Energy Saving Concepts and Opportunities for the Metal Casting Industry

7. Thollander P, Ottosson M (2010) Energy management practices in Swedish energy-intensive industries. J Clean Prod 18:1125-1133 . doi: 10.1016/J.JCLEPRO.2010.04.011

8. Mehrabi H, Jolly M, Salonitis K (2016) Road-Mapping Towards a Sustainable Lower Energy Foundry. Springer, Cham, pp 251-260

9. Salonitis K, Jolly MR, Zeng B, Mehrabi H (2016) Improvements in energy consumption and environmental impact by novel single shot melting process for casting. J Clean Prod 137:1532-1542 . doi: 10.1016/J.JCLEPRO.2016.06.165

10. Pagone E, Jolly M, Salonitis K (2016) The Development of a Tool to Promote Sustainability in Casting Processes. Procedia CIRP 55:53-58 . doi: 10.1016/J.PROCIR.2016.09.001

11. Barkhudarov M, Hirt C (1995) Casting simulation: Mold filling and solidification--Benchmark calculations using FLOW-3D ${ }^{\circledR}$

12. Reilly C, Green NR, Jolly MR, Gebelin J-C (2013) The modelling of oxide film entrainment in casting systems using computational modelling. Appl Math Model 37:8451-8466 . doi: 10.1016/J.APM.2013.03.061

13. Imafuku I, Chijiiwa K (1983) A Mathematical Model for Shrinkage Cavity Prediction in Steel Castings. Trans Am Foundrymen's Soc 91:527-540

14. Hirt CW (2004) Modeling shrinkage induced micro-porosity. St Fe, New Mex USA Flow Sci Inc

15. Ravi B (2010) Casting Simulation - Best Practices. Trans 58th IFC

16. Zeng J, Koitzsch R, Pfeifer H, Friedrich B (2009) Numerical simulation of the twin-roll casting process of magnesium alloy strip. J Mater Process Technol 209:2321-2328 . doi: 10.1016/J.JMATPROTEC.2008.05.032

17. Nimbulkar SL, Dalu RS (2016) Design optimization of gating and feeding system through simulation technique for sand casting of wear plate. Perspect Sci 8:39-42 . doi: 10.1016/J.PISC.2016.03.001 
18. Kermanpur A, Mahmoudi S, Hajipour A (2008) Numerical simulation of metal flow and solidification in the multi-cavity casting moulds of automotive components. J Mater Process Technol 206:62-68 . doi:

10.1016/J.JMATPROTEC.2007.12.004

19. Krimpenis A, Benardos PG, Vosniakos G-C, Koukouvitaki A (2006) Simulation-based selection of optimum pressure die-casting process parameters using neural nets and genetic algorithms. Int J Adv Manuf Technol 27:509-517 . doi: 10.1007/s00170-004-2218-0

20. Dabade UA, Bhedasgaonkar RC (2013) Casting Defect Analysis using Design of Experiments (DoE) and Computer Aided Casting Simulation Technique.

Procedia CIRP 7:616-621 . doi: 10.1016/J.PROCIR.2013.06.042

21. Keste AA, Gawande SH, Sarkar C (2016) Design optimization of precision casting for residual stress reduction. J Comput Des Eng 3:140-150 . doi: 10.1016/J.JCDE.2015.10.003

22. Jolly M, Dai X, Zeng B (2012) Energy Saving in the foundry industry by using the CRIMSON single shot up-casting process. Foundry Trade J Int 186:317-324

23. Ali F, Tzanidakis K, Goulos I, et al (2015) Multi-Objective Optimization of Conceptual Rotorcraft Powerplants: Trade-off Between Rotorcraft Fuel Efficiency and Environmental Impact. J Eng Gas Turbines Power 137:071201 . doi: $10.1115 / 1.4029103$

24. Ali F, Tzanidakis K, Goulos I, et al (2015) Multi-objective Optimization of a Regenerative Rotorcraft Powerplant: Trade-off Between Overall Engine Weight and Fuel Economy. J Eng Gas Turbines Power 137:121201 . doi: $10.1115 / 1.4030634$

25. FLOW-3D | CFD software | Multiphysics Modeling | Numerical Simulation. https://www.flow3d.com/.

26. Powell MJD (Michael JD, Buhmann MD (Martin D, Iserles A (1997) Approximation theory and optimization : tributes to M.J.D. Powell. Cambridge University Press

27. Deb K, Pratap A, Agarwal S, Meyarivan T (2002) A fast and elitist multiobjective genetic algorithm: NSGA-II. IEEE Trans Evol Comput 6:182197 . doi: 10.1109/4235.996017

28. Platypus - Multiobjective Optimization in Python - Platypus documentation. http://platypus.readthedocs.io/en/latest/\#. 


\title{
A computational framework towards energy efficient casting processes
}

\author{
Papanikolaou, Michail
}

Springer

Papanikolaou M, Pagone E, Salonitis K, et al., (2019) A computational framework towards energy efficient casting processes. In: Dao D., et al., (Eds) Sustainable Design and Manufacturing 2018. KES-SDM 2018. Smart Innovation, Systems and Technologies, Volume 130, pp. 263-276

https://doi.org/10.1007/978-3-030-04290-5_27

Downloaded from Cranfield Library Services E-Repository 